\title{
THE NOVEMBER MEETING IN SOUTH BEND
}

The three hundred ninety-first meeting of the American Mathematical Society was held at the University of Notre Dame, South Bend, Indiana, on Friday and Saturday, November 27-28, 1942 in connection with the Centennial Celebration of the University of Notre Dame. The attendance was about seventy including the following fifty-one members of the Society:

Leonidas Alaoglu, E. S. Allen, P. H. Anderson, W. L. Ayres, Henry Blumberg, L. M. Blumenthal, I. W. Burr, R. V. Churchill, C. E. Clark, A. H. Copeland, C. C. Craig, R. P. Eddy, Samuel Eilenberg, G. M. Ewing, N. J. Fine, C. H. Fischer, J. H. Giese, Michael Golomb, Cornelius Gouwens, L. M. Graves, G. E. Hay, M. H. Heins, T. H. Hildebrandt, A. S. Householder, M. H. Ingraham, J. H. Kenna, Joseph Landin, H. W. Linscheid, Eugene Lukacs, G. W. Mackey, Karl Menger, A. N. Milgram, C. J. Nesbitt, Jerzy Neyman, Ivan Niven, C. D. Olds, P. M. Pepper, Maxwell Reade, G. E. Schweigert, A. H. Smith, W. S. Snyder, C. E. Springer, A. H. Stone, D. M. Stone, R. M. Thrall, Bernard Vinograde, Abraham Wald, M. S. Webster, G. W. Whitehead, A. L. Whiteman, J. W. T. Youngs.

Sessions for the reading of contributed papers were held on Friday afternoon with Professor L. M. Blumenthal presiding and on Saturday morning with Professor R. V. Churchill presiding. Jointly with this meeting the University of Notre Dame held its annual Mathematical Symposium, the subject being Modern statistics. On Friday afternoon prior to the Society session Professor Jerzy Neyman of the University of California spoke on Theory of confidence intervals and at the close of the Society session Professor Abraham Wald of Columbia University spoke on Outline of a general theory of siatistical inference. On Saturday morning before the session of the Society there were two more addresses of the Symposium: Asymptotic properties of the likelihood ratio test by Professor Wald and On a class of tests equivalent in the limit to the likelihood ratio tests by Professor Neyman. The presiding officers of the Symposium sessions were Professor C. C. Craig, Dean M. H. Ingraham, Professors Sewall Wright and A. H. Copeland. The Symposium addresses contributed greatly to the interest of the Society meetings. On Friday evening those attending the meetings were the guests of the University of Notre Dame at a buffet supper.

Titles and cross references to the abstracts of the papers read follow below. Papers 1 to 6 were read Friday afternoon, papers 7 to 12 on Saturday morning, and papers 13 to 20 , whose abstract numbers are followed by the letter $t$, were read by title. Dr. G. S. Young was introduced by Professor W. L. Ayres. Paper 8 was read by Professor Nesbitt, 9 by Mr. Reed and 11 by Professor Smith. 
1. Maxwell Reade: Remarks on a paper of Beckenbach. (Abstract 49-1-40.)

2. P. M. Pepper: $A$ new method for imbedding theorems. (Abstract 49-1-76.)

3. A. N. Milgram: A topologically invariant metric property of simple closed curves. (Abstract 49-1-98.)

4. L. M. Graves: Metrisation of weak convergence in Banach spaces. (Abstract 49-1-96.)

5. G. S. Young: Sets of axioms for the plane. Preliminary report. (Abstract 49-1-102.)

6. Karl Menger: Statistical generalizations of metric geometry. (Abstract 49-1-75.)

7. Ivan Niven: An unsolved case of the Waring problem. (Abstract 49-1-10.)

8. C. J. Nesbitt and W. M. Scott: Some remarks on algebras over an algebraically closed field. (Abstract 49-1-9.)

9. Karl Menger and S. G. Reed: On a surface not intersecting the set $R_{3}^{1}$. (Abstract 49-1-97.)

10. G. M. Ewing: Minimizing an integral on a class of continuous curves. (Abstract 49-1-30.)

11. H. F. S. Jonah and A. H. Smith: Zero order summability of the series conjugate to the derived Fourier series. (Abstract 49-1-35.)

12. C. E. Springer: Dual goedesics on a surface. (Abstract 49-1-80.)

13. M. A. Basoco: On the Fourier developments of a certain class of theta quotients. (Abstract 48-11-310-t.)

14. Raphael Salem: On some singular monotonic functions which are strictly increasing. (Abstract 49-1-41-t.)

15. Ivan Niven: The Pell equation in quadratic fields. (Abstract 49-1-11-t.)

16. Maxwell Reade: On a theorem of Fédoroff and Binney. (Abstract 49-1-39-t.)

17. J. E. Wilkins: A class of functions in the calculus of variations for multiple integrals in parametric form. (Abstract 49-1-52-t.)

18. Brockway McMillan: Networks of mechanisms. Preliminary report. (Abstract 49-1-68-t.)

19. Max Coral: Solution of quasi-linear partial differential equations through a characteristic initial curve. (Abstract 49-1-29-t.)

20. R. L. Swain: Approximate isometries in bounded spaces. (Abstract 49-1-100-t.)

\author{
W. L. Ayres, \\ Associate Secretary
}

